\title{
Socio-demographic factors Influencing Postpartum care joint decision making and use of Family Planning among the young population in South- West, Nigeria
}

Obasanjo Afolabi Bolarinwa ( $\sim$ bolarinwaobasanjo@hotmail.com )

University of KwaZulu-Natal, South Africa https://orcid.org/0000-0002-9208-6408

Olalekan Seun Olagunju

Obafemi Awolowo University, Nigeria https://orcid.org/0000-0001-8394-133X

Akintayo Olaniyan

Obafemi Awolowo University, Nigeria https://orcid.org/0000-0001-5651-6303

Tesleem Babalola

University of KwaZulu-Natal, South Africa https://orcid.org/0000-0003-1568-3134

\section{Research Article}

Keywords: Postpartum, Young Population, Family planning, South-West, Nigeria

Posted Date: September 9th, 2020

DOl: https://doi.org/10.21203/rs.3.rs-72603/v1

License: (c) (i) This work is licensed under a Creative Commons Attribution 4.0 International License.

Read Full License 


\section{Abstract}

Background: Population explosion continues to be a serious concern across the globe. The current world population estimate of 7.7 billion people is expected to increase to 9.7 billion by the year 2050. Despite the projected growth, recent reports have shown that approximately, six million infants died before their first birthday, and thirty-five women die per hour as a result of pregnancy and childbirth related complications. Postpartum Family Planning (PPFP) has been recommended to help protect women from unplanned pregnancies within the first six weeks of giving birth. An effective postpartum contraceptive utilization in developing countries could reduce the rate of maternal and perinatal morbidity and mortality. Thus, this study was aimed at examining the socio-demographic factors that influence postpartum care joint decision making and the use of family planning among the young female population in South West, Nigeria.

Methods: The study involved the use of primary dataset collected among young mothers aged 15-30 years in South West, Nigeria, in 2019. Inclusion criteria including having a child in the year preceding the survey. One hundred forty respondents were interviewed in three senatorial districts to give 420 respondents, and the data collected were analyzed adopting univariate, bivariate, and multivariate measures.

Results: The findings from the study showed that respondents across all the age groups were more likely to jointly agree with their spouse/partner concerning the use of family planning, and this was significant for the age group 25-29 years. Also, there was a significant association between family planning usage and a healthy, meaningful relationship between joint decision, and communication on the use of family planning after delivery $(P$-value $<0.05)$.

Conclusion: This study revealed the importance of male partners in couple's decision towards uptake of family planning services. It recommends that focused community orientation, and awareness strategies, including reproductive health education for couples, should be implemented at community grass root levels

\section{Introduction}

Globally, approximately six million children died before their first birthday in 2016 and thirty-five women dying every hour as a result of pregnancy and childbirth related complications. In Nigeria, the Maternal Mortality Ratio (MMR) is still on the high side of 576 per 100,000 live births $^{3}$. Evidences has shown that obstetric deaths could be reduced by 20 percent through the correct adoption of family planning (FP $)^{4,5}$, statistics also showed that an increase of 15 to 17 percent of contraceptives utilization decreases population growth by one birth per woman ${ }^{6}$.

Evidence has shown that FP is a cost-effective public health intervention with the potential to reduce both maternal and child mortality ${ }^{8}$. Family planning (FP) low utilization is one of the significant issues in 
many developing countries with poor access to maternal and child health care services. ${ }^{6,7}$ There is an unmet need for family planning among estimated 215 million women in these countries and 82 percent of unintended pregnancies could be a could be attributed to the FP unmet need. ${ }^{9}$ Inaccessibility to effective FP is particularly high in the postpartum period ${ }^{10,11}$. Hence, $20 \%$ of birth in low-income countries usually occur before 24 months of the previous delivery ${ }^{2}$. This number will undoubtedly increase as the global population continues to grow, and as large proportion of young population enter their childbearing years ${ }^{8}$.

A demographic health survey of four countries found that a lower proportion (25\%) of women in Kenya adopted postpartum family planning (PPFP) by six months after delivery, while $35 \%$ do at one year. Studies have shown that the need for contraceptives varies during a woman's reproductive years, but demand is highest during the postpartum period ${ }^{12}$. The first six weeks of giving birth to protect women from unplanned pregnancies by spacing the birth-to-pregnancy interval by at least two years and the inter-birth range by at least three years is termed Postpartum Family Planning (PPFP) ${ }^{2,13-16}$. The use of effective postpartum contraceptive methods in less developed countries could prevent poor maternal, perinatal, and neonatal health outcomes, including stillbirth, prematurity, low birth weight, neonatal and maternal mortality ${ }^{2,13-16}$. The postpartum period is particularly crucial for a woman's life; because many routine interventions are provided to mothers during this time ${ }^{11}$.

Global efforts aimed at redressing gender-based inequalities through empowering women have also been increasingly laying emphasis on encouraging greater male participation in women's health. Empowering women and increasing male involvement in maternal health care-seeking are both viewed as essential approaches to reduce rate of preventable maternal morbidity and mortality worldwide. ${ }^{17,18}$ Though women's autonomy is critical, recent evidence suggests opposition by husband or partner led to contraceptive inaccessibility among 10 percent of women with unmet need for family planning. ${ }^{19}$ There is growing recognition that reproductive health should be a joint responsibility of men and women, given that men often have significant influence on couple's contraceptive use ${ }^{20}$. Furthermore, the role and importance of husbands need to be considered when developing family planning services and programs $^{21}$.

Compared to men, women often lack decision-making power to allocate resources for health care seeking, most especially in contexts where men determine whether and under what conditions their spouses will use health services ${ }^{16}$. Decisions about adopting appropriate FP such as using contraceptives for either spacing or liming childbirth are often strongly shaped by spousal relationships. ${ }^{6}$ Surveys from sub-Saharan Africa show that most women would be willing for their male partners to participate in maternal health care ${ }^{13}$. Studies in the past tend to argue that concordant joint decision making is favorable for better maternal health outcomes than male-dominated or women-dominated decision making. There is a theoretical assumption that effective communication and shared control over 
resources, reflected in the couple's concordance in joint decision makings, have the potential to overcome husband's opposition to contraceptive use when there is a disagreement on regulating childbirth 7,18 .

Disregarding the contraceptive needs of postpartum women are missed opportunities in health service delivery to ensure that every woman and her family can enjoy the health, social, and economic benefits of family planning. ${ }^{17}$, Deliberate promotion of postpartum family planning has shown promising results. Most of the evidence is limited to middle-and high-income countries ${ }^{22}$. Still, the overall adoption in Nigeria is very low among the young female population, and literature is equally limited.

Male partner opposition of contraception is often cited as an obstacle and is associated with lower contraception use by women ending preventable maternal mortality. Thus, perinatal mortality necessarily involves engaging with families and communities. Male partners, in particular, exert a considerable influence on women's use of reproductive health services and participate in decisions that affect health outcomes $^{13}$. To better understand the joint decision making process of FP, this study was aimed at examining the socio-demographic factors influencing postpartum care joint decision making and the use of family planning among the young population in South-West, Nigeria.

\section{Aims}

This study was limited to the primary dataset collected among young mothers aged 15-30 years in SouthWest, Nigeria. The young mothers are those who already had a child in the last year, and this study is expected to provide insight on how socio-demographic factors Influencing Postpartum care joint decision making and the use of Family planning.

\section{Main Research Question/Objective}

The question of interest is to identify and discuss how socio-demographic factors Influencing Postpartum care joint decision making and the use of Family planning among the young female population in South West, Nigeria.

\section{Significance of the research}

Conducting a study on how socio-demographic factors Influencing Postpartum care joint decision making and use of Family planning in South West, Nigeria is particularly relevant for policymakers since more information is needed about hidden factors that are significantly influencing the non/low use of family planning in Nigeria and knowing the factors could contribute to the development of programs that are particularly relevant to use of family planning in Nigeria.

\section{Methods}

\section{Sample size}


The study population comprised young mothers (within reproductive age 15 - 30 years) who already had a child in the last year. The study area was purposively chosen to capture contraceptive use among this group. The primary data collection was done in four senatorial districts of Osun state, Nigeria. One hundred forty respondents were interviewed in each senatorial district to give 420 respondents in total.

\section{Research Instrument}

The study employed a cross-sectional method of data collection that is a quantitative method of data collection. Semi-structured questionnaires were used to collect information on socio-demographic characteristics, family planning use, Postnatal/Postpartum care, joint decision, and support among young mothers. (Please see supplementary material on questionnaire Table, $\mathrm{S}_{1}$ below).

\section{Ethical considerations}

The researchers ensured that the informed consent of the respondent was sought by explaining the purpose of the study; anonymity was maintained by not including their names, and confidentiality was assured. Before administering the questionnaire, a copy of the research protocol was submitted for a full review to the Research and Ethics committee of Institute of Public Health, Obafemi Awolowo University, Ile-Ife (IPH, OAU) and approval for this study was obtained with IPHOAU/12/1446. (Please see supplementary material on institution ethical approval, figure $\mathrm{S}_{1}$ below).

\section{Results}

Table 1 below represents the respondent's socio-demographic. The table shows that more than half of the respondents were between age $25-29$ years $(60 \%)$ with an average age of 26 years. Respondent's level of education shows that the majority (85.9\%) attended secondary (42.1\%) and post-secondary (43.8\%). More than half of the respondents practice Christianity $(66.4 \%)$ as religion. The table also revealed that majority of the respondents $(90.7 \%)$ were employed, almost all were living with their husband/partner (80.5\%), $81.2 \%$ of the husband of respondents married just one wife and more than half had $1-2$ children before the study with average children ever born of 2.2 children.

Table 1: Respondent's Socio-demographics characteristics 


\begin{tabular}{|c|c|c|}
\hline Variable & Frequency $\mathrm{N}=420$ & Percent \\
\hline \multicolumn{3}{|l|}{ Age } \\
\hline Below 20 & 19 & 4.5 \\
\hline $20-24$ & 99 & 23.6 \\
\hline $25-29$ & 252 & 60.0 \\
\hline $30+$ & 50 & 11.9 \\
\hline \multicolumn{3}{|c|}{ Mean age: 26 years, SD: 3.4} \\
\hline \multicolumn{3}{|c|}{ Highest level of education } \\
\hline No formal education & 15 & 3.7 \\
\hline Primary & 44 & 10.4 \\
\hline Secondary & 177 & 42.1 \\
\hline Post-secondary & 184 & 43.8 \\
\hline \multicolumn{3}{|l|}{ Religion } \\
\hline Christianity & 279 & 66.4 \\
\hline Islam & 141 & 33.6 \\
\hline \multicolumn{3}{|l|}{ Occupation status } \\
\hline Unemployed & 39 & 9.3 \\
\hline Employed & 381 & 90.7 \\
\hline \multicolumn{3}{|l|}{ Living arrangement } \\
\hline Living with you & 338 & 80.5 \\
\hline Living elsewhere & 82 & 19.5 \\
\hline \multicolumn{3}{|l|}{ Family type } \\
\hline Monogamous & 341 & 81.2 \\
\hline Polygamous & 79 & 18.8 \\
\hline \multicolumn{3}{|l|}{ Children ever born } \\
\hline $1-2$ & 255 & 60.7 \\
\hline $3+$ & 165 & 39.3 \\
\hline Mean CEB: 2.2, SD: 1. & & \\
\hline
\end{tabular}


Fig 1 below represents family planning usage and consent from the husband. The figure shows that 8 out of every ten respondents were currently using a method of family planning, and 7 out of every 10 seek permission from their husband before using family planning.

Fig 2 represent spousal communication on the number of children, family planning usage after delivery, reducing workload during pregnancy and after birth, healthy pregnancy, proper nutrition during pregnancy, and after delivery and money matters. The figure shows that at least 7 out of 10 respondents have excellent communication with their husbands/partners.

Table 2 below shows the logistic regression of communication on joint decisions concerning family planning. The table shows that respondents that had excellent communication concerning money matters, number of children, use of family planning after delivery, healthy pregnancy, and reduction of workload during and after childbirth were more likely to agree to use a method of family planning jointly. This analysis was only statically significant for the respondent that had excellent communication concerning the number of children, the use of family planning, and reducing workload during pregnancy.

Table 2 Logistic regression of spousal communication on the joint decision of family planning

\begin{tabular}{|c|c|c|c|}
\hline Variable & Odd ratio & P-value & Confidence interval \\
\hline \multicolumn{4}{|c|}{ Communication on money matters: $\mathrm{RC}=$ Poor } \\
\hline Good & 2.15 & 0.394 & $0.3687-12.5766$ \\
\hline \multicolumn{4}{|c|}{ Communication on the number of children: $\mathrm{RC}=$ Poor } \\
\hline Good & 2.56 & $0.017^{\star}$ & $1.1845-5.5167$ \\
\hline \multicolumn{4}{|c|}{ Communication on the use of family planning: $\mathrm{RC}=$ Poor } \\
\hline Good & 7.26 & $0.000 \star$ & $3.2752-16.0783$ \\
\hline \multicolumn{4}{|c|}{ Communication on healthy pregnancy: $\mathrm{RC}=$ Poor } \\
\hline Good & 1.26 & 0.775 & $0.2626-6.0085$ \\
\hline \multicolumn{4}{|c|}{ Communication on proper nutrition during pregnancy: $\mathrm{RC}=$ Poor } \\
\hline Good & 1.04 & 0.959 & $0.1996-5.4687$ \\
\hline \multicolumn{4}{|c|}{ Communication on reducing workload during pregnancy: $\mathrm{RC}=\mathrm{Poo}$} \\
\hline Good & 2.65 & $0.049 *$ & $1.0060-6.9964$ \\
\hline Constant & 0.08 & 0.000 & $0.0345-0.1984$ \\
\hline
\end{tabular}

Table 3 below shows the logistic regression of respondent's socio-demographic against family planning usage. This is to identify respondent's socio-demographic that influence family planning usage. The table revealed that respondents across all the age groups were more likely to use family planning, and this was 
significant for the age group 25-29 years and 30 years and above. Level of education shows that respondent with the primary school was more likely to use any method of family planning and respondents with secondary and post-secondary were less likely to use family planning but the analysis only significant for respondents with primary education in this study.

Respondents' employment status was statistically significant in that respondents who were employed were more likely to use a method of family planning.

Concerning the respondent's husband socio-demographic, the table shows that respondents whose husbands were employed were more likely to use a method of family planning, and this statistically significant in this study. A respondent with a husband that had secondary and post-secondary was more likely to use a method of family planning but only statistically significant with post-secondary. Respondents whose husband age were between the ages group 30-34 years and 35-39 years were more likely to family planning, and respondents whose husband age was above 39 years were less likely to seek permission, and this was statistically significant for respondents whose husband age were 30-34 years and 40 years and above.

Table 3: Logistic regression of respondent socio-demographic on use of family planning 


\begin{tabular}{|c|c|c|c|}
\hline Variable & Odd ratio & P-value & Confidence interval \\
\hline \multicolumn{4}{|c|}{ Respondent age: RC= Below 20} \\
\hline $20-24$ & 4.01 & 0.113 & $0.7215-22.2680$ \\
\hline $25-29$ & 7.34 & $0.019 *$ & $1.3790-39.0923$ \\
\hline $30+$ & 31.36 & $0.003^{\star}$ & $3.2935-298.5587$ \\
\hline \multicolumn{4}{|c|}{ Respondent level of education: RC= No formal education } \\
\hline Primary & 70.33 & $0.012^{*}$ & $2.5279-1956.873$ \\
\hline Secondary & 0.60 & 0.622 & $0.0789-4.5690$ \\
\hline Post-secondary & 0.32 & 0.314 & $0.0358-2.9172$ \\
\hline \multicolumn{4}{|c|}{ Respondent religion: $\mathrm{RC}=$ Christianity } \\
\hline Islam & 1.42 & 0.623 & $0.3507-5.7487$ \\
\hline \multicolumn{4}{|c|}{ Respondent employment status: RC = Unemployed } \\
\hline Employed & 6.83 & $0.005^{\star}$ & $1.8030-25.8600$ \\
\hline \multicolumn{4}{|c|}{ Living arrangement: $\mathrm{RC}=$ Living with you } \\
\hline Living elsewhere & 0.12 & $0.000 *$ & $0.0393-0.3606$ \\
\hline \multicolumn{4}{|c|}{ Family type: RC=Monogamous } \\
\hline Polygamous & 0.46 & 0.152 & $0.1605-1.3293$ \\
\hline \multicolumn{4}{|c|}{ Number of children: $\mathrm{RC}=1-2$} \\
\hline $3+$ & 0.43 & 0.144 & $0.1385-1.3337$ \\
\hline \multicolumn{4}{|c|}{ Husband religion: $\mathrm{RC}=$ Christianity } \\
\hline Islam & 0.66 & 0.528 & $0.1804-2.4076$ \\
\hline \multicolumn{4}{|c|}{ Husband employment status: RC=Unemployed } \\
\hline Employed & 28.63 & $0.000 *$ & $6.2717-130.7041$ \\
\hline \multicolumn{4}{|c|}{ Husband level of education: RC=Primary } \\
\hline Secondary & 1.30 & 0.795 & $0.1767-9.6069$ \\
\hline Post-secondary & 8.59 & $0.043^{*}$ & $1.0741-68.7154$ \\
\hline \multicolumn{4}{|c|}{ Husband age: $\mathrm{RC}=\mathbf{2 5 - 2 9}$} \\
\hline $30-34$ & 3.80 & $0.044^{\star}$ & $1.0354-13.9732$ \\
\hline $35-39$ & 1.82 & 0.365 & $0.4999-6.5912$ \\
\hline
\end{tabular}




\begin{tabular}{|llll|}
\hline $40+$ & 0.11 & $0.004^{*}$ & $0.0263-0.4893$ \\
\hline Constant & $\mathbf{0 . 0 1}$ & $\mathbf{0 . 0 0 4}$ & $\mathbf{0 . 0 0 0 2}-\mathbf{0 . 2 0 7 0}$ \\
\hline
\end{tabular}

Table 4 below shows the logistic regression of communication on husband consent concerning family planning. The table shows that respondents that had an excellent conversation concerning money matters, number of children, use of family planning after delivery, healthy pregnancy, and reduction of workload during and after childbirth were more likely to seek permission. Respondents with excellent communication concerning proper nutrition during pregnancy and after delivery were less likely to seek consent. This analysis was statically significant for the respondent that had excellent communication concerning the number of children, use of family planning, and the reduction of workload during pregnancy and after delivery.

Table 4: Logistic regression of respondent spousal communication on husband consent

\begin{tabular}{|c|c|c|c|}
\hline Variable & Odd ratio & P-value & Confidence interval \\
\hline \multicolumn{4}{|c|}{ Communication on money matters: $\mathrm{RC}=$ Poor } \\
\hline Good & 1.85 & 0.497 & $0.3142-10.8556$ \\
\hline \multicolumn{4}{|c|}{ Communication on the number of children: RC=Poor } \\
\hline Good & 2.55 & $0.022^{\star}$ & $1.1413-5.6782$ \\
\hline \multicolumn{4}{|c|}{ Communication on the use of family planning: $\mathrm{RC}=$ Poor } \\
\hline Good & 6.28 & $0.000^{\star}$ & $2.7768-14.1899$ \\
\hline \multicolumn{4}{|c|}{ Communication on healthy pregnancy: $\mathrm{RC}=$ Poor } \\
\hline Good & 1.47 & 0.626 & $0.3123-6.9293$ \\
\hline \multicolumn{4}{|c|}{ Communication on proper nutrition during pregnancy: $\mathrm{RC}=\mathrm{Poor}$} \\
\hline Good & 0.81 & 0.807 & $0.1505-4.3660$ \\
\hline \multicolumn{4}{|c|}{ Communication on reducing workload during pregnancy: $\mathrm{RC}=\mathrm{Po}$} \\
\hline Good & 2.94 & $0.028^{*}$ & $1.1227-7.7010$ \\
\hline Constant & 0.13 & 0.000 & $0.0633-0.2827$ \\
\hline
\end{tabular}

Table 5 below shows the logistic regression of respondent's socio-demographic on joint decisions of family planning. This is to identify the respondent's socio-demographic that influence joint decisions around the use of family planning. The table revealed that respondents across all the age groups were more likely to jointly agree with their spouse/partner concerning the use of family planning, and this was significant for the age group 25-29 years. Level of education shows that respondents with primary education were more likely to jointly agree with their spouse/partner concerning use a method of family 
planning, and respondents with secondary and post-secondary were less likely to use family planning, but the analysis only significant for respondents with primary education.

Respondents' employment status was statistically significant in that respondents who were employed were more likely to jointly agree with their spouse/partner concerning using a method of family planning. Living arrangements show that respondents living elsewhere were less likely to mutually agree with their spouse/partner concerning use a method of family planning, and this was statistically significant.

Concerning the respondent's husband socio-demographic, the table shows that respondents who husband were employed were more likely to jointly agree with their spouse concerning using a method of family planning and this statistically significant in this study. Respondents with a husband that had secondary and post-secondary were more likely to jointly agree with their spouse concerning use a method of family planning, and this was statistically significant secondary and post-secondary. Respondent whose husband age were between the age group 30-34 years and 35-39 years were more likely to jointly agree with their spouse and respondent whose husband age were above 39 years were less likely to mutually agree with their spouse concerning the use of family planning and this was statistically significant for respondent whose husband age was 40 years and above.

Table 5 Logistic regression of respondent socio-demographic on the joint decision of family planning. 


\begin{tabular}{|c|c|c|c|}
\hline Variable & Odd ratio & P-value & Confidence interval \\
\hline \multicolumn{4}{|c|}{ Respondent age: $\mathrm{RC}=$ Below 20} \\
\hline $20-24$ & 3.91 & 0.143 & $0.6313-24.2368$ \\
\hline $25-29$ & 9.1 & $0.013^{\star}$ & $1.5830-53.3062$ \\
\hline $30+$ & 2.6 & 0.365 & $0.3182-22.5040$ \\
\hline \multicolumn{4}{|c|}{ Respondent level of education: RC= No formal education } \\
\hline Primary & 263.46 & $0.013^{*}$ & $3.1948-21726.89$ \\
\hline Secondary & 0.15 & 0.096 & $0.0158-1.4009$ \\
\hline Post-secondary & 0.12 & 0.077 & $0.0111-1.2567$ \\
\hline \multicolumn{4}{|c|}{ Respondent religion: $\mathrm{RC}=$ Christianity } \\
\hline Islam & 0.53 & 0.320 & $0.1520-1.8515$ \\
\hline \multicolumn{4}{|c|}{ Respondent employment status: RC = Unemployed } \\
\hline Employed & 29.67 & $0.000 *$ & $6.3348-138.9927$ \\
\hline \multicolumn{4}{|c|}{ Living arrangement: $\mathrm{RC}=$ Living with you } \\
\hline Living elsewhere & 0.04 & $0.000 *$ & $0.0115-0.1110$ \\
\hline \multicolumn{4}{|c|}{ Family type: RC=Monogamous } \\
\hline Polygamous & 0.39 & 0.087 & $0.1335-1.1457$ \\
\hline \multicolumn{4}{|c|}{ Number of children: $\mathrm{RC}=1-2$} \\
\hline $3+$ & 1.22 & 0.723 & $0.4011-3.7300$ \\
\hline \multicolumn{4}{|c|}{ Husband religion: $\mathrm{RC}=$ Christianity } \\
\hline Islam & 0.84 & 0.771 & $0.2616-2.7025$ \\
\hline \multicolumn{4}{|c|}{ Husband employment status: RC=Unemployed } \\
\hline Employed & 105.04 & $0.000 *$ & $12.6570-871.675$ \\
\hline \multicolumn{4}{|c|}{ Husband level of education: RC=Primary } \\
\hline Secondary & 16.62 & $0.021^{\star}$ & $1.5252-181.1394$ \\
\hline Post-secondary & 145.31 & $0.000 *$ & $9.7949-2155.648$ \\
\hline \multicolumn{4}{|c|}{ Husband age: $\mathrm{RC}=\mathbf{2 5 - 2 9}$} \\
\hline $30-34$ & 3.05 & 0.107 & $0.7862-11.805$ \\
\hline $35-39$ & 1.02 & 0.979 & $0.2717-3.8160$ \\
\hline
\end{tabular}




\begin{tabular}{|llll|}
\hline $40+$ & 0.05 & $0.001^{*}$ & $0.0090-0.2734$ \\
\hline Constant & $\mathbf{0 . 0 0}$ & $\mathbf{0 . 0 0 0}$ & $\mathbf{0 . 0 0 0 0 - \mathbf { 0 . 0 0 7 9 }}$ \\
\hline
\end{tabular}

Table 6 below shows the association between joint decision, communication on the use of family planning after delivery, and family planning use. The table shows that there is an association between mutual decision, communication on the use of family planning after birth, and the use of family planning.

Table 6: Association between joint decision, communication on the use of FP after delivery and family planning use.

\begin{tabular}{|lllc|}
\hline Variable & \multicolumn{4}{l|}{ Currently using a method of FP } \\
\hline Joint decision & No & Yes & Total \\
\hline No & $77(72.6)$ & $29(27.4)$ & 106 \\
\hline Yes & $0(0.0)$ & $314(100.0)$ & 314 \\
\hline Chi-square, P-value & Chi2: 279.29 P-value: $0.000 *$ \\
\hline Communication on the use of FP after delivery & \\
\hline Poor & $54(58.7)$ & $38(41.3)$ & 92 \\
\hline Good & $23(7.0)$ & $305(93.0)$ & 328 \\
\hline Chi-square, P-value & Chi2: 128.18 P-value: $0.000 *$ \\
\hline
\end{tabular}

\section{Discussion}

The study examined the socio-demographic factors influencing postpartum care, joint decision making, and family planning usge among the young population in South-West Nigeria. Findings from the study revealed that most of the respondents were active users of a method of family planning, and most of them sought permission from their husbands before using family planning. The results also showed that a good number of respondents have excellent communication with their husbands/partners. This means most of the respondents had husbands who were actively involved and supportive in the reproductive health of their wives, which has been correlated by other studies.

The study shows that there are an association and a strong significant relationship between joint decision, communication on the use of family planning after delivery, and the use of family planning. This simply means to tackle low use of family planning during the postpartum period among the young population, joint spousal decision, and communication on the use of family planning during postpartum should be encouraged among couples.

Study results showed that excellent communication concerning the number of children, use of family planning, and reduction of workload during pregnancy and after delivery was statistically significant with 
seeking spousal consent. The study also revealed a significant association between respondents that had excellent communication concerning money matters, the number of children, the use of family planning after delivery, healthy pregnancy and reduction of workload during and after birth and using a method of family planning and the use of family planning. Power inequalities between couples have consistently challenged open communication between partners with regards to reproductive health matters and the uptake of reproductive health services. Still, these findings represent a marked improvement in family planning uptake outcomes.

The study findings showed that age, employment status, level of education, and living arrangement were all statistically significant with seeking permission from husbands for the use of family planning. These findings are related to other previous studies that have explored the relationship between sociodemographic factors and spousal consent for the uptake of family planning.

\section{Conclusion And Recommendation}

The power balance between couples plays an essential role in the health-seeking behavior of women. This study revealed that most of the respondents reported that their husbands were generally supportive and showed positive attitudes towards their uptake of family planning services. A focused community orientation, and awareness strategies, including reproductive health education for couples, should be implemented at local government levels in the various communities. Also, strengthening the Community Health Extension Workers (CHEWs) activities directed in increasing awareness and improving attitude towards family planning services are recommended to empower and inform women to seek these services.

\section{Declarations}

Competing interests: The authors declare no competing interests.

\section{Reference}

1. United Nations DoE, Social Affairs PD. World Population Prospects 2019: Data Booklet (ST/ESA/SER. A/424). In: United Nations New York, NY; 2019.

2. Yonas Tadesse S, Emiru AA, Tafere TE, Asresie MB. Women's Autonomy Decision Making Power on Postpartum Modern Contraceptive Use and Associated Factors in North West Ethiopia. Advances in Public Health. 2019;2019.

3. Chukwuji CN, Tsafe AG, Sayudi S, Yusuf Z, Zakariya J. Awareness, Access and Utilization of Family Planning Information in Zamfara State, Nigeria. Library Philosophy and Practice (e-journal). 2018;771.

4. Organization WH. Programming strategies for postpartum family planning. 2013. 
5. Coomson JI, Manu A. Determinants of modern contraceptive use among postpartum women in two health facilities in urban Ghana: a cross-sectional study. Contraception and reproductive medicine. 2019;4(1):17.

6. Islam AZ. Factors affecting modern contraceptive use among fecund young women in Bangladesh: does couples' joint participation in household decision making matter? Reproductive health. 2018;15(1):112.

7. Chitashvili T, Holschneider S, Clark P. Improving quality of postpartum family planning in lowresource settings. A framework for policy makers managers and medical care providers. 2016.

8. Tran NT, Gaffield ME, Seuc A, et al. Effectiveness of a package of postpartum family planning interventions on the uptake of contraceptive methods until twelve months postpartum in Burkina Faso and the Democratic Republic of Congo: the YAM DAABO study protocol. BMC health services research. 2018;18(1):439.

9. Akinlo A, Bisiriyu A, Esimai O. Influence of use of maternal health care on postpartum contraception in Nigeria. 2013.

10. Mutombo N, Bakibinga P. The effect of joint contraceptive decisions on the use of Injectables, LongActing and Permanent Methods (ILAPMs) among married female (15-49) contraceptive users in Zambia: a cross-sectional study. Reproductive health. 2014;11(1):51.

11. Sm M, Kamal SMM, Anisur M, Mphil R, Towhiduzzaman. The Influence of Family Planning Workers on Postpartum Contraceptive use among Women in Bangladesh. Journal of Family Medicine \& Community Health. 2017;4.

12. Jalang'o R, Thuita F, Barasa SO, Njoroge P. Determinants of contraceptive use among postpartum women in a county hospital in rural KENYA. BMC public health. 2017;17(1):604.

13. Acharya DR, Bell JS, Simkhada P, Van Teijlingen ER, Regmi PR. Women's autonomy in household decision-making: a demographic study in Nepal. Reproductive health. 2010;7(1):15.

14. Daniele MA, Ganaba R, Sarrassat S, et al. Involving male partners in maternity care in Burkina Faso: a randomized controlled trial. Bulletin of the World Health Organization. 2018;96(7):450.

15. Blazer C, Prata N. Postpartum family planning: current evidence on successful interventions. Open Access Journal of Contraception. 2016;7:53.

16. Gay J. High-Impact Practices in Family Planning (HIPs), “. Adolescent-Friendly Contraceptive Services: Mainstreaming Adolescent-Friendly Elements Into Existing Contraceptive Services.

17. Jennings $L, N a M$, Cherewick $M$, Hindin M, Mullany $B$, Ahmed $S$. Women's empowerment and male involvement in antenatal care: analyses of Demographic and Health Surveys (DHS) in selected African countries. BMC pregnancy and childbirth. 2014;14(1):297.

18. Nigatu D, Gebremariam A, Abera M, Setegn T, Deribe K. Factors associated with women's autonomy regarding maternal and child health care utilization in Bale Zone: a community based cross-sectional study. BMC women's health. 2014;14(1):79.

19. Uddin J, Pulok MH, Sabah MN-U. Correlates of unmet need for contraception in Bangladesh: does couples' concordance in household decision making matter? Contraception. 2016;94(1):18-26. 
20. Kabagenyi A, Jennings L, Reid A, Nalwadda G, Ntozi J, Atuyambe L. Barriers to male involvement in contraceptive uptake and reproductive health services: a qualitative study of men and women's perceptions in two rural districts in Uganda. Reproductive health. 2014;11(1):21.

21. Eshete A, Adissu Y. Women's Joint Decision on Contraceptive Use in Gedeo Zone, Southern Ethiopia: A Community Based Comparative Cross-Sectional Study. International journal of family medicine. 2017;2017.

22. Ayiasi RM, Muhumuza C, Bukenya J, Orach CG. The effect of prenatal counselling on postpartum family planning use among early postpartum women in Masindi and Kiryandongo districts, Uganda. Pan African Medical Journal. 2015;21(1).

\section{Figures}

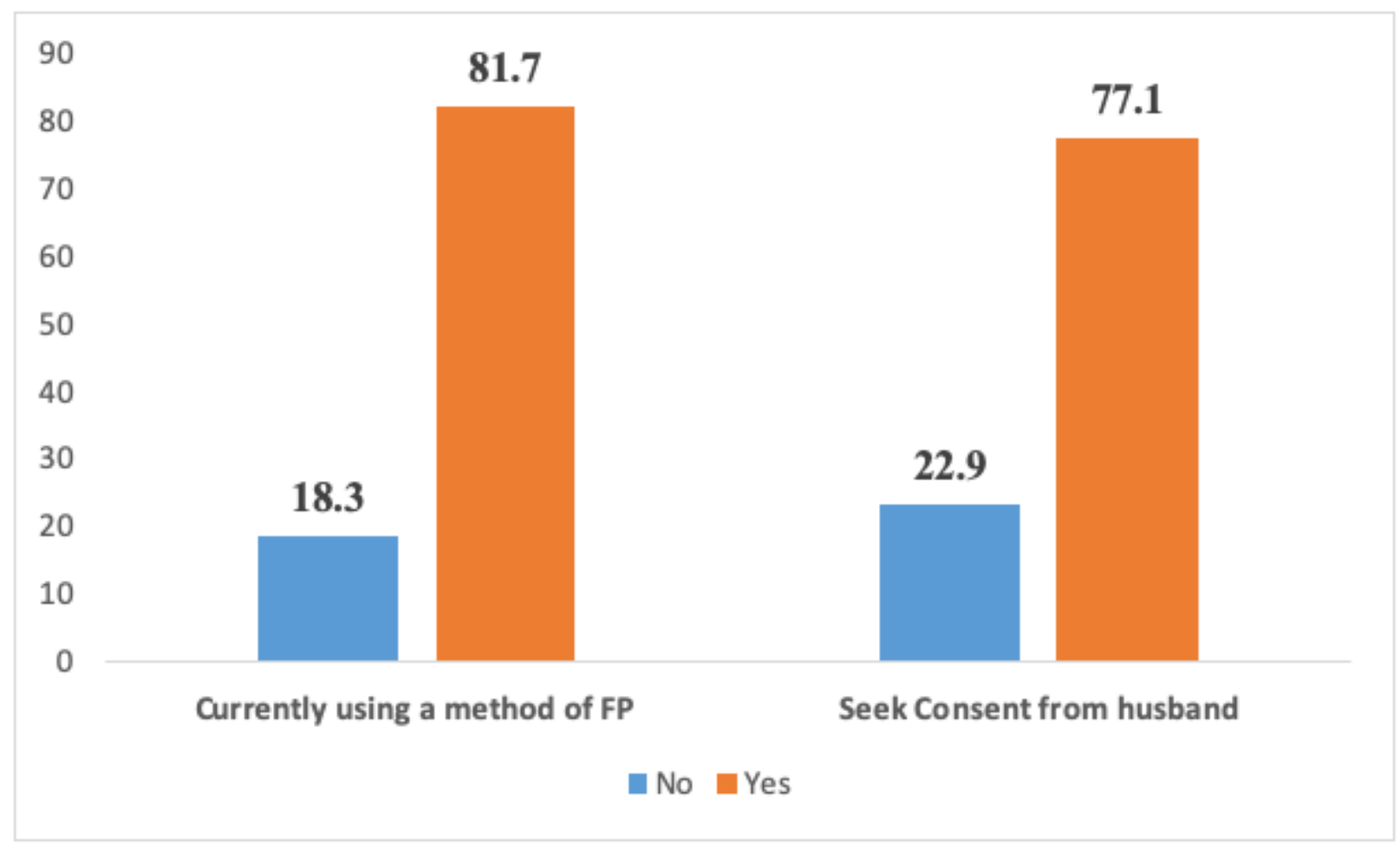

\section{Figure 1}

The husband gives respondent use of family planning and consent 


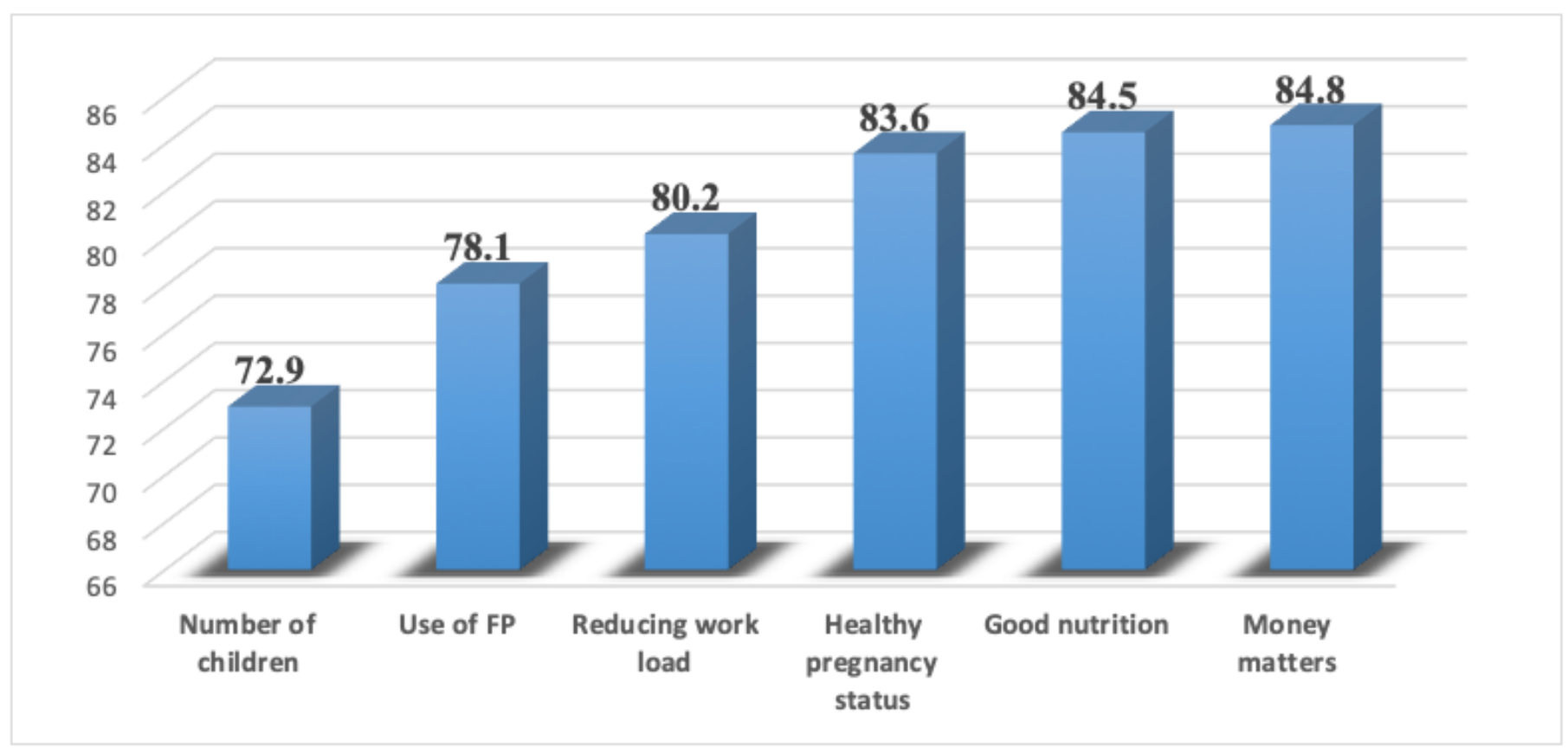

Figure 2

Spousal communication 